\title{
Effects of Root Restriction on Ultrastructure of Phloem Tissues in Grape Berry
}

\author{
ZhaoSen Xie \\ Department of Plant Science, College of Agriculture and Biology, Shanghai \\ Jiaotong University, Dongchuan Road 800, Shanghai 200240, China
}

Charles F. Forney

Atlantic Food and Horticulture Research Centre, Agriculture and Agri-Food Canada, 32 Main Street, Kentville, Nova Scotia B4N 1J5 Canada

\section{WenPing $\mathrm{Xu}$ and ShiPing Wang ${ }^{1}$ \\ Department of Plant Science, College of Agriculture and Biology, Shanghai Jiaotong University, Dongchuan Road 800, Shanghai 200240, China}

Additional index words. root restriction, grape berry, ultrastructure, phloem

\begin{abstract}
In this study, the ultrastructure of phloem and its surrounding parenchyma cells in the developing grape berry produced under root restriction or without (control) was for the first time systematically investigated through transmission electron microscopy during the entire developmental process of the berry. The results showed that root restriction increased the number of plasmodesmata between sieve elements (SE) and companion cells (CC) and between the SE/CC complex and phloem parenchyma cells. Sieve elements in fruit produced under root restriction were smaller in size than those from the control treatment, but $\mathrm{CC}$ were bigger than in the control treatment. During the first rapid growth phase of the grape berry, there was denser cytoplasm in the CC produced under root restriction having more abundant mitochondria, endoplasmic reticulum, multivesicular bodies, vesicles, and plastids than in control fruit. During the second rapid growth phase of the grape berry, $\mathrm{CC}$ under root restriction showed more serious plasmolysis. Cytoplasmic contents such as vesicles were fused into the vacuole of which the tonoplast nearly disappeared in the phloem parenchyma cells, and cytoplasmic contents in fruit cells produced under root restriction became denser than the control treatment. These results demonstrated that grape berry adapted to the root restriction stress through ultrastructure variation of the phloem, and this variation explained the increase of photosynthate accumulation in the grape berry observed under root restriction.
\end{abstract}

Root restriction is a powerful approach to improve the efficiency of agricultural resource use and to control the size of the shoot and partitioning of assimilates between vegetative and reproductive organs (Carmi, 1986). In recent years, root restriction has been developed to manipulate tree vigor and control the environment of root systems in grape (Wang et al., 2001), apple (Myers, 1992), mandarin (Yakushiji et al., 1996), peach (Boland et al., 1994; Costa et al., 1992), cherry (Webster et al., 1997), and persimmon (Ogawa et al., 1997). In previous reports, it has been demonstrated that plants subjected to root restriction display distinctive differences in growth habit compared with those under normal field cultivation (Goto et al., 2002; Wang et al., 2001). Root restriction can reduce photosynthetic productivity and growth of the shoot. However, root restriction also can increase root mass and the

Received for publication 23 Apr. 2009. Accepted for publication 3 June 2009.

${ }^{1}$ To whom reprint requests should be addressed; e-mail fruit@sjtu.edu.cn.
(Fisher and Oparka, 1996; Patrick, 1997). The phloem unloading pathway includes both symplasmic and apoplasmic routes (Patrick, 1997). Evidence from several plant species suggests that a symplasmic pathway predominates in most sink tissues (Patrick, 1997; van Bel, 2003). The predominance of the symplasmic unloading pathway has been associated with greater transport capacity and lower resistance (Patrick, 1997; Patrick and Offler, 1996; van Bel, 2003). However, several studies revealed that the unloading path appears to be influenced by sink development and function and hence is a dynamic rather than a static property of a particular sink type (Patrick, 1990; Patrick and Offler, 1996). Roberts et al. (1997) revealed that the symplasmic phloem unloading pathway may be blocked during sink-to-source transition in tobacco (Nicotiana tabacum) leaves. Zhang et al. (2006) found that a shift of phloem unloading from the symplasmic to the apoplasmic pathway occurs during grape berry development. Elucidation of the cellular pathway of phloem unloading under root restriction is central to reaching a mechanistic understanding of this phenomenon. Grape (Vitis vinifera) berry is one of the economically important sink organs in which sugar accumulation is a major determinant of yield and quality. The vascular system of the berry includes dorsal (peripheral), ventral (central), and ovular vascular bundles. Knowledge of the structure of the phloem contributes to the understanding of metabolic mechanisms and the relationship between phloem structure and function.

Although studies have been reported on the effects of root restriction on photosynthesis in grape leaves, vine growth, and nitrogen metabolism (Yang et al., 2007; Zhu et al., 2006), information on assimilate accumulation in grape berry and the mechanisms that regulate sugar accumulation under root restriction are still not understood. Phloem of the fruit is involved in assimilate accumulation in the grape berry. Ultrastucture of phloem is thought to be related to assimilate accumulation in the grape berry. The objective of the present research was to study the effects of root restriction on the ultrastructure of phloem tissue and its surrounding parenchyma tissue of the grape berry during berry development. In this study, the ultrastructural characteristics of phloem tissue in the grape sible for assimilate movement from the sieve elements (SE) to the recipient sink cells

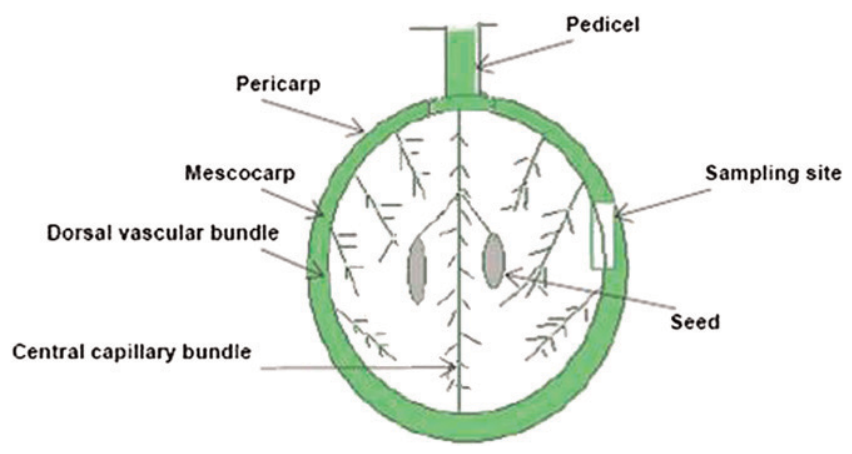

Fig. 1. Structure of the grape berry and sampling site used for ultrastructure determination. 
berry were observed from plants subjected to root restriction and compared with that from control plants.

\section{Materials and Methods}

Plant material. The experiment was carried out during the 2008 growing season at the experimental farm at Shanghai Jiaotong University, Shanghai, China (long. $31^{\circ} 0^{\prime} 18^{\prime \prime}$ $\mathrm{N}$, lat. $121^{\circ} 24^{\prime} 31^{\prime \prime} \mathrm{E}$ ). Two groups of 20 uniform 3-year-old grapevines (Vitis Vinifera $\times$ Vitis Labrasca cv. Kyoho) were selected. Vines in one group were subjected to root restriction by being planted in 10-L plastic pots in a mixture of sand, loam, and perlite $(1: 1: 1)$. Vines in the second group were planted in a raised bed $(50 \mathrm{~cm}$ deep $)$ in the same medium and served as the controls. The two groups of grape vines had been planted in plastic pots and the raised bed for 2 years. Each vine was pruned in late winter of 2007 so that the number of retained buds on a grapevine was three to five. All grapevines were staked upright and the shoots were trained vertically in spring of 2008. One good strong shoot on each vine was left and other shoots were removed. Only the basal fruit cluster was retained on the one remaining shoot after bloom. The number of berries in this cluster was thinned to $\approx 50$. The space between each vine was $60 \mathrm{~cm}$. From February to September, vines were maintained in a ventilated greenhouse under natural light at the experimental farm. The greenhouse covering material was plastic sheeting with a percent transmission of $\approx 87 \%$. The greenhouse used natural ventilation to provide uniform air flow throughout the entire greenhouse, which prevented the air temperature inside the greenhouse from rising too high above the outside air temperature. After budburst, $1 \mathrm{~L}$ of complete liquid fertilizer (Hydro Co. Ltd., Eilat, Israel), containing $32.7 \mathrm{mg} \mathrm{NO}_{3}^{-}, 22.0 \mathrm{mg} \mathrm{NH}_{4}, 120 \mathrm{mg}_{2} \mathrm{O}_{5}$, $120 \mathrm{mg} \mathrm{K}_{2} \mathrm{O}$, $20.0 \mathrm{mg} \mathrm{MgO}, 0.167 \mathrm{mg}$ boron, $0.067 \mathrm{mg}$ copper, $0.467 \mathrm{mg}$ EDTA-Fe, 2.667 mg manganese, $0.027 \mathrm{mg}$ molybdenum, and $0.167 \mathrm{mg}$ zinc, was applied to each vine once a week. Tensiometers were placed at a $15-\mathrm{cm}$ depth in the rooting zone to monitor soil moisture. Grapevines were irrigated by a drip irrigation system to maintain the soil moisture $-3.0 \mathrm{kPa}$ or greater from replanting to veraison and $-5.0 \mathrm{kPa}$ or greater from veraison to harvest, respectively.

Berry growth measurements. Thirty berries on three grapevines in each group were individually tagged and numbered, and for individual berries, diameters were measured every $3 \mathrm{~d}$ at dawn (0600 to $0700 \mathrm{HR}$ ) with a pair of calipers ( $\pm 0.02 \mathrm{~mm}$ precision) from $20 \mathrm{~d}$ after anthesis to the ripening stage, $\approx 80$ $\mathrm{d}$ after anthesis. On designated dates, 20 berries in one group were randomly sampled and taken back to the laboratory in an icebox within $30 \mathrm{~min}$ of harvest for measurement of total soluble solids.

Determinations of flesh total soluble solids. Juice samples were squeezed from

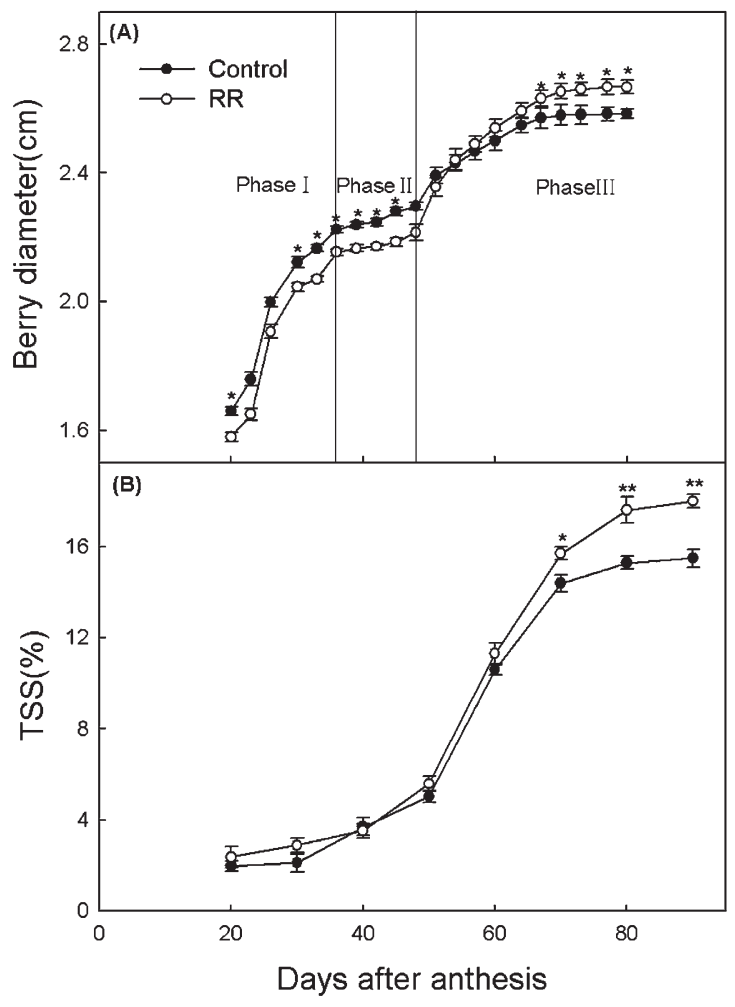

Fig. 2. Changes in berry diameter (A) and total soluble solids (B) for fruit produced with root restriction (RR) or without (control) during berry growth and development.
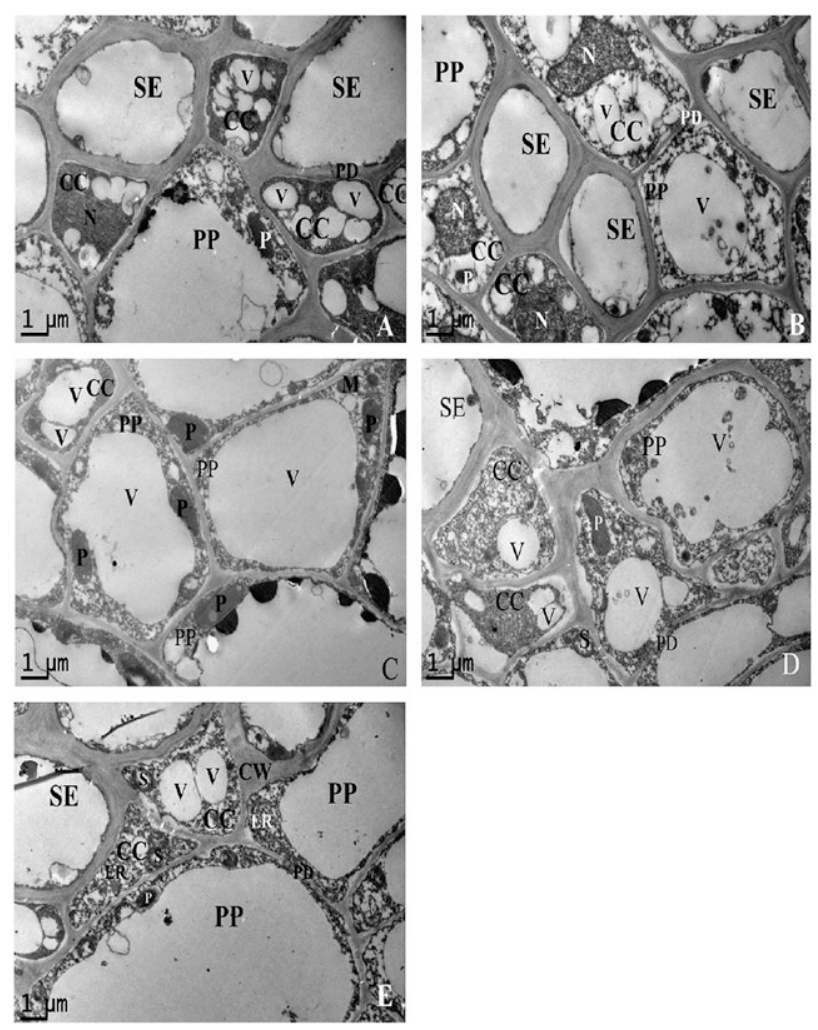

Fig. 3. Ultrastructure of the phloem in the dorsal vascular bundle and its surrounding parechymatous cells during Phase I of berry growth. (A) A transverse section of a dorsal vascular bundle in a control fruit showing a large sieve element (SE) with a small companion cell (CC). (B) A transverse section of a dorsal vascular bundle in a fruit produced under root restriction showing a smaller SE but a larger CC than in control fruit. (C) Phloem parenchyma cells in a control fruit showing many plastids on the edge of the cell. (D) Phloem parenchyma cells in a grape berry produced under root restriction showing fewer plastids than in control fruit. (E) Plasmodesmata between phloem parenchyma cells (PP) and CC and between PP and PP in a fruit produced under root restriction. 

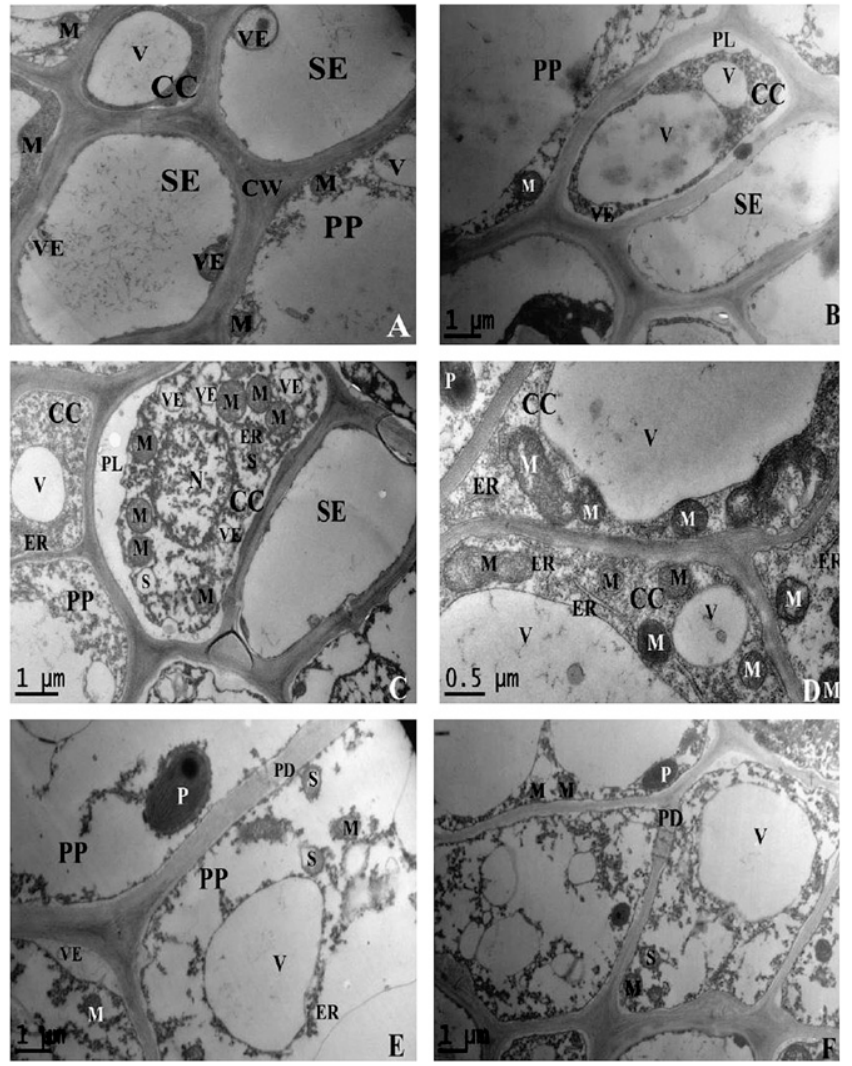

Fig. 4. Ultrastructure of the phloem in the dorsal vascular bundle and its surrounding parechymatous cells during Phase II of berry growth. (A) A mature sieve element (SE)/companion cell (CC) complex in a control fruit showing vesicles and electron-opaque materials in SE. (B) A mature SE/CC complex in a control fruit, showing plasmolysis in CC. (C) A mature SE/CC complex in a fruit produced under root restriction showing more serious plasmolysis in CC. (D) A mature SE/CC complex in a fruit produced under root restriction showing dense cytoplasm with more multivesicular than control fruit. (E) Phloem parenchyma cells in a control fruit showing dense cytoplasm in parenchyma cell. (F) Phloem parenchyma cells in a fruit produced under root restriction showing dense cytoplasm and starch grain.

Table 1 . The plasmodesmal density (no. plasmodesmata/ $\mu \mathrm{m}$ ) between different cells in the unloading zone of the grape berry just before ripening.

\begin{tabular}{|c|c|c|c|c|c|}
\hline \multirow[b]{2}{*}{ Treatment } & \multicolumn{5}{|c|}{ Plasmodesmal density (no. of plasmodesmata/ $\mu \mathrm{m}$ ) } \\
\hline & $\overline{\mathrm{SE} / \mathrm{CC}}$ & $\mathrm{SE} / \mathrm{PP}$ & $\mathrm{CC} / \mathrm{PP}$ & $\mathrm{PP} / \mathrm{PP}$ & $\mathrm{SE} / \mathrm{SE}$ \\
\hline Control & 2.16 & 1.58 & 0.75 & 1.53 & 0 \\
\hline RR & 3.21 & 2.38 & 1.13 & 1.68 & 0 \\
\hline Significance & $*$ & $*$ & $*$ & NS & NS \\
\hline
\end{tabular}

pieces taken from opposite ends of a vertical fruit slice, centrifuged at $10,000 \times \mathrm{g}$ for 10 min, and total soluble solids (TSS) were determined on the supernatant by refractometry (ATAGO Master-M, Tokyo, Japan).

Tissue preparation for structural observation. The method described by Zhang et al. (2001a) was used to prepare tissue for structural observation. The vascular bundle zone (sepal bundles, including major and minor bundles; Fig. 1) was cut into small cubes $\left(\approx 2\right.$ to $\left.3 \mathrm{~mm}^{3}\right)$ that were immediately fixed with $5 \%(\mathrm{v} / \mathrm{v})$ glutaraldehyde in $100 \mathrm{~mm}$ precooled phosphate buffer ( $\mathrm{pH}$ 7.0) for $6 \mathrm{~h}$. The penetration of the glutaraldehyde buffer was enhanced by placing the tissue in the fixative under vacuum. After an extensive rinse with cold phosphate buffer $(\mathrm{pH} 7.0)$, the tissue cubes were postfixed in $1 \%(\mathrm{w} / \mathrm{v}) \mathrm{OsO}_{4}$ overnight at room temperature. After another extensive rinse with the same buffer, the samples were dehydrated through a graded ethanol series $(30 \%$ to $100 \%)$ and $100 \%$ acetone, and infiltrated for $24 \mathrm{~h}$ with Spurr resin at room temperature. Polymerization was conducted at $68{ }^{\circ} \mathrm{C}$ for $8 \mathrm{~h}$. Ultrathin sections ( $\approx 60$ to $90 \mathrm{~nm}$ in thickness) were mounted on 100-mesh copper grids coated with a $0.3 \%$ Formvar film for the ultrastructural observations, which were conducted using a JEM-100S transmission electron microscope (JEOL Ltd, Tokyo, Japan).

Measurement of plasmodesmal density. The method for measurement of plasmodesmal density was adapted from Kempers et al. (1998) and used in our previous study (Zhang et al., 2004). Five series of transverse ultrathin sections were prepared from the Spurrinfiltrated flesh samples in which each group was cut at a distance of $\approx 20 \mu \mathrm{m}$ from the previous one. From each group, six ultrathin sections were picked at random and put on the 100-mesh copper grids. Five fields, each consisting of phloem and its surrounding phloem parenchyma cells (PP), were observed from each ultrathin section. Plasmodesmata were counted at all cell interfaces, i.e., the interfaces between sieve elements (SE)/companion cells (CC), SE/PP, CC/PP, and $\mathrm{PP} / \mathrm{PP}$ in each selected field. The results of the plasmodesmal counting were given as the number of plasmodesmata per micron of specific cell/cell interface length in the transverse section, which is referred to as plasmodesmal density (Fisher, 1990).

Statistical analysis. The comparison of pairs of values was analyzed by $t$ test and levels of significance are represented by $* P<$ $0.05, * * P<0.01$, and NS, nonsignificant.

\section{Results}

Grape berries exhibit a double sigmoid growth pattern (Fig. 2A). Phase I is the first rapid growth phase of the grape berry during which the berry is formed and the seed embryos are produced. Phase II is the lag of berry growth after the first growth phase (Phase I). After this period of slow growth (Phase II), Phase III, a second rapid growth phase, takes place, which coincides with the onset of ripening.

During Phase I, berry diameter increased rapidly, and there was no significant difference in berry growth between the root restriction treatment and the control. However, the rate of berry growth under the root restriction treatment was more rapid than that of the control fruit during Phase III growth (Fig. 2A). In addition, TSS content increased during Phase III. Total soluble solids content of fruit grown under root restriction was higher during most of berry development and was significantly higher at harvest than in control fruit (Fig. 2B).

Sieve element and companion cell of grape berry. Phloem formation in grape berry occurred during Phase I, in which the development of sieve elements and $\mathrm{CC}$ in the grape berry could be observed (Fig. 3A-B). The CC contained numerous small vacuoles and a large nucleus in the dense cytoplasm, and the cytoplasm was rich in plastids, mitochondria, and rough endoplasmic reticulum (ER) (Fig. 3A-B). Sieve elements under root restriction were smaller in size than those from the control treatment, but $\mathrm{CC}$ were bigger than those from the control treatment (Fig. 3A-B). Companion cells under root restriction had larger nuclei and more mitochondria, vacuoles, and rough ER than in the control treatment (Fig. 3B).

During Phase II growth of the grape berry, the structure of mature phloem could be observed. There were intact organelle and dense cytoplasm in the mature CC. Companion cells in fruit under root restriction had larger and more mitochondria than control fruit (Fig. 4A-D).

During Phase III, grape berries had dramatic changes in the structure of the SE and 

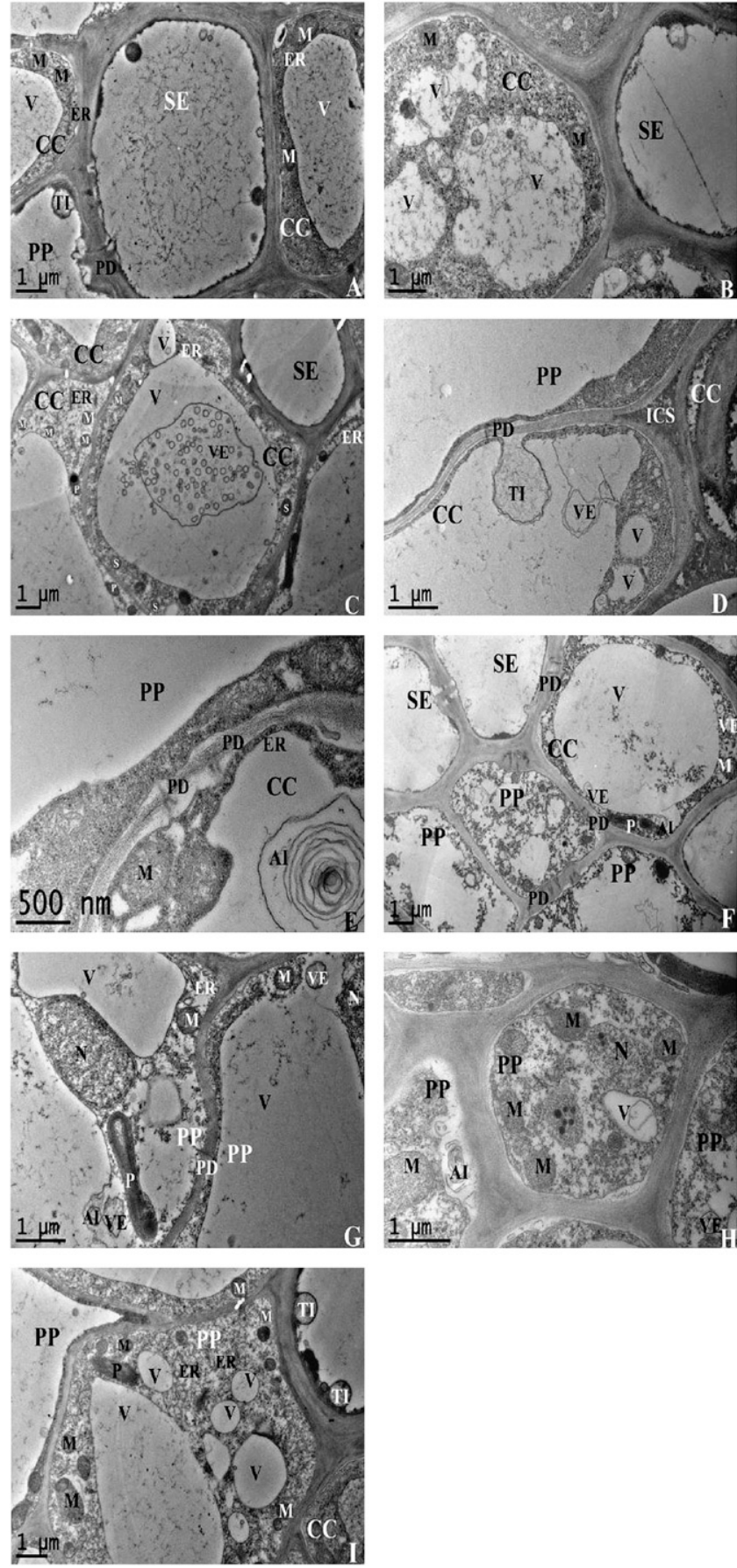

Fig. 5. Ultrastructure of the phloem in the dorsal vascular bundle and its surrounding parechymatous cells during Phase III of fruit growth. (A) Ultrastructure of mature sieve element (SE)/companion cell (CC) complex in a control grape berry showing the vesicle-like and microfibril-like structures in SE and CC. (B) Ultrastructure of mature SE/CC complex in a fruit produced under root restriction showing the tonoplast partially disappeared. (C) Ultrastructure of CC complex in a fruit produced under root restriction showing many vesicles in CC. (D) Ultrastructure of CC complex in a fruit produced under root restriction showing tonoplast invagination (TI) of the vacuole and vesicles in the vacuole. $(\mathbf{E})$ Ultrastructure of CC complex in a fruit produced under root restriction showing aphakia (AI) in companion cell. (F) Phloem parenchyma cells (PP) in a control fruit showing electron-dense materials in PP. (G) Ultrastructure of organelles in PP in a control fruit showing degradation of plastids and mitochondrion in PP. (H) Phloem parenchyma cells in a fruit produced under root restriction showing electron-denser materials in PP than in control fruit. Ultrastructure of organelle in PP in a fruit produced under root restriction showing more mitochondrion in PP than in control fruit.

$\mathrm{CC}$ in fruit from both the root restriction and control treatments. Granular materials were visible near the cell wall of the SE, CC, and parenchyma cells for both treatments (Fig. $5 \mathrm{~A}-\mathrm{C})$. Companion cells under root restric- tion showed more serious plasmolysis. (Fig. 5B-C). Aphakia (AI) is visible in $\mathrm{CC}$ under root restriction (Fig. 5E). The presence of $\mathrm{AI}$ in $\mathrm{CC}$ indicates that organelles degrade during this phase. A large number of vesicles formed on the edge of the plasma membrane for both treatments (Figs. 5B and E). A number of vesicles merged in vacuoles of $\mathrm{CC}$ under root restriction (Fig. 5D).

Phloem parenchyma cells of grape berry. During Phase I, the outer phloem parenchyma cells contained a large central vacuole, but some phloem parenchyma cells adjacent to the sieve elements were lower in cell volume and vacuolization extent (Fig. 3C-E). Root restriction reduced phloem parenchyma cell size, but the number of mitochondrion in the phloem parenchyma cells was more than in the control treatment (Fig. 3C-E). The number of plastids in cells from plants under root restriction was less than those from the control treatment (Fig. 3C-D).

During Phase II, the ultrastructure of phloem parenchyma cells has a clear change (Fig. 4E-F). Dense cytoplasm with abundant mitochondria, ER, multivesicular bodies, vesicles, plastids, and starch grain were observed in phloem parenchyma cells produced under root restriction (Fig. 4F).

During Phase III, phloem parenchyma cells presented an obvious process of senescence and degeneration (Fig. 5F-I); the cell walls lost their integrity or even disappeared in some cells under root restriction (Fig. $5 \mathrm{H}-$ I); some vesicles, a quantity of waddinglike debris of dissolved cytoplasmic components, and some lipid bodies were observed (Fig. 5F-I); cytoplasmic contents such as vesicles were fused into the vacuole of which the tonoplast nearly disappeared (Figs. 5F and $\mathrm{H}$ ); and cytoplasmic contents under root restriction became denser than that of the control treatment (Figs. 5F and $\mathrm{H}$ ). The mitochondria remained intact and numerous; and the plasma membranes appeared to maintain their integrity for both treatments, which could be related to the maintenance of berry growth or ripening (Fig. 5F-I).

Plasmodesmata. During Phases I and II, numerous plasmodesmata were found in the phloem between the SE and the CC (Fig. 6H), between the SE/CC complex and the phloem parenchyma cells (Figs. 6C-E and I), and between the phloem parenchyma cells (Figs. 6A-B and G), which indicates that the phloem had symplastic integration that could facilitate easy unloading from the SE into both $\mathrm{CC}$ and phloem parenchyma cells through a symplasmic pathway. Root restriction increased the number of plasmodesmata between the SE and the CC and between the $\mathrm{SE} / \mathrm{CC}$ complex and the phloem parenchyma cells; but plasmodesmata between the phloem parenchyma cells were not significantly different in number between the SE/CC complex to the complex during Phase III growth of the grape berry (Table 1).

During Phase III, most of the plasmodesmata between the SE/CC complex and the surrounding phloem parenchyma cells was shown to be blocked by electron-opaque globules (Fig. 6E-G), indicating symplastic isolation between the SE/CC complex and the surrounding parenchyma cells during this phase. 

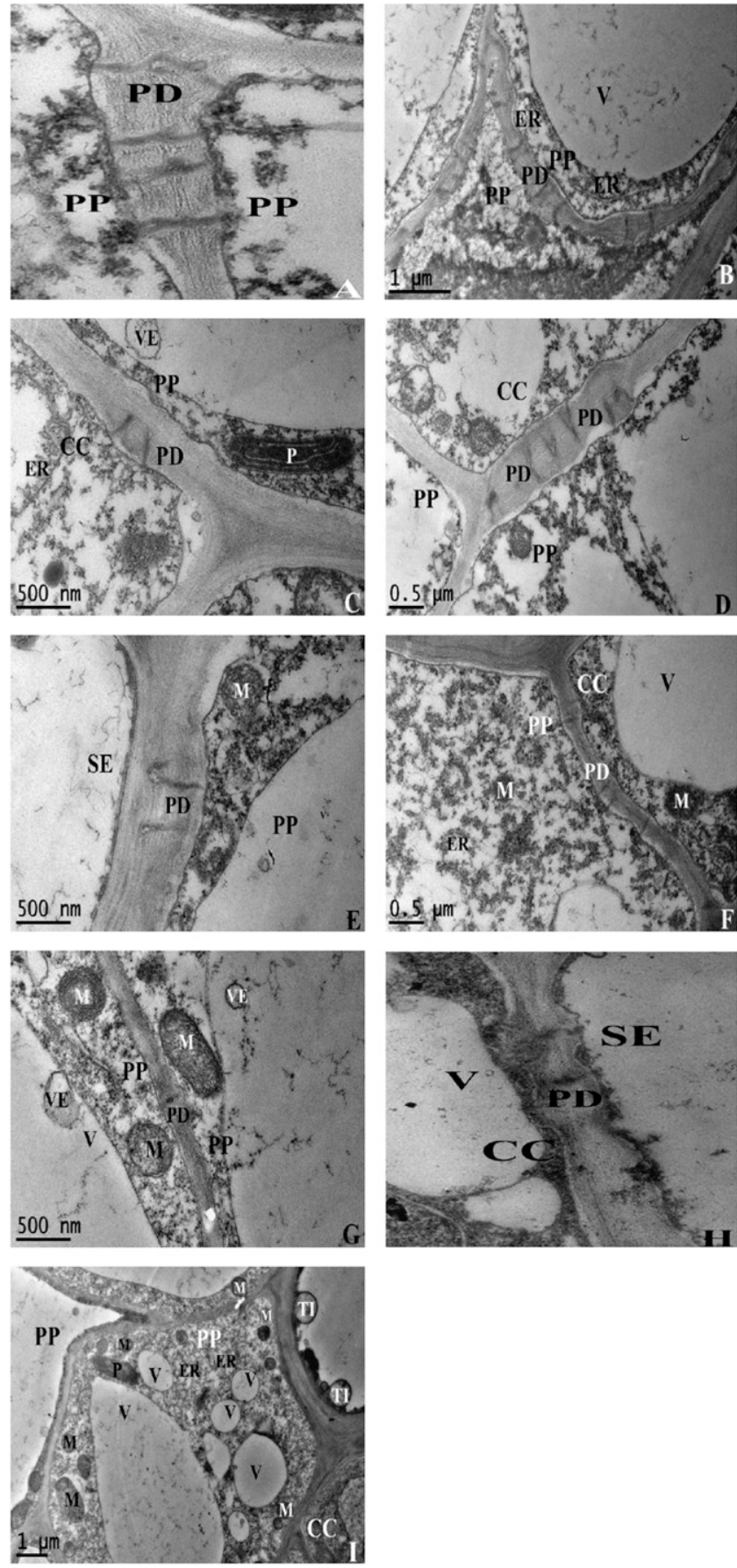

Fig. 6. Ultrastructure of plasmodesma of the phloem in the dorsal vascular bundle and its surrounding phloem parenchyma cells during all stages of grape berry development. (A) Plasmodesma between phloem parenchyma cells in a control fruit during Phase I of fruit growth. (B) Plasmodesma between phloem parenchyma cells in a fruit grown under root restriction during Phase I of berry growth. (C) Plasmodesma between companion cells and parenchyma cell in a control fruit during Phase II of fruit growth. (D) Plasmodesma between companion cells and parenchyma cell in fruit produced under root restriction during Phase II of berry growth. (E) Plasmodesma between sieve elements and parenchyma cell in a control fruit during Phase III of fruit growth. $(\mathbf{F}-\mathbf{G})$ Plasmodesma between parenchyma cells in fruit produced under root restriction during Phase III of fruit growth. (H) Plasmodesma between sieve elements and companion cell in a control fruit during Phase III of fruit growth. (I) Plasmodesma between companion cells and parenchyma cell in a fruit produced under root restriction during Phase III of fruit growth.

\section{Discussion}

We show in this study that root restriction affected the ultrastructure of the phloem tissue during grape berry development. Cytological studies revealed that the SE/CC com- plexes in the phloem of the peripheral vascular bundles in developing fruit have a symplasmic connection with their surrounding PP through plasmodesmal channels. Therefore, the grape berry follows a predominantly symplasmic phloem unloading pathway during Phases I and II of fruit development. Zhang et al. (2006) reported that the shift of the phloem unloading pathway, symplasmic to apoplasmic pathway, occurred at the onset of ripening. In this study, we also found plasmodesmas were blocked by electron-opaque globules at the onset of ripening. Because of symplasmic isolation between the SE/CC complexes and the PP during Phase III, the pathway of phloem unloading appears to be through an apoplasmic transmembrane route at this stage of development.

Under root restriction, more plasmodesmatas were observed between the SE and the $\mathrm{CC}$ and between the SE/CC complexes and the phloem parenchyma cells than in the control treatment. This suggests an increased potential for symplastic transport under root restriction. Although sugar accumulation in the grape berry was through the apoplasmic pathway during Phase III growth, the denser plasmodesmata resulting from the root restriction stress may help to keep cells intact. Root restriction stress reduced the size of the SE but increased the size of $\mathrm{CC}$ when compared with the control treatment, and the cytoplasm in the $\mathrm{CC}$ was denser with abundant mitochondria, ER, multivesicular bodies, and vesicles.

The predominantly apoplasmic unloading during the Phase III growth of the grape berry requires an efficient mechanism for sugar transport across the membranes (Zhang et al., 2006). Root restriction stress promoted TSS accumulation in the grape berry during this growth phase. The elevated soluble sugar levels may be favorable to maintain the turgor pressure gradient through an osmoregulatory mechanism (Patrick, 1997; van Bel, 2003). In these sinks, a mechanism to maintain the driving force for sugar translocation by the sink is necessary. Plasmolysis in the $\mathrm{CC}$ was visible; nevertheless, there were still numerous intact mitochondria in the $\mathrm{CC}$ for the two treatments, and the number of mitochondria in the $\mathrm{CC}$ under root restriction was more than in the control treatment. The plasma membranes also appeared intact for both treatments. The tonoplast of the companion cells and PP was observed to possess invaginations for the two treatments during Phase III growth. This suggests that the transport of photoassimilates through apoplastic unloading using vesicles may have been occurring. More vesicles were fused into the vacuole of the PP under root restriction. The increase of sugar accumulation in the grape berry under root restriction may be related to this formation of vesicles.

Wang et al. (2001) reported that water stress occurred almost everyday because of the smaller amount of available water under root restriction. During maturation, moderate water stress retards secondary shoot growth without notably affecting photosynthetic activity (Carbonneau and Deloire, 2001), thus favoring the redistribution of sugar into the berries and the perennial organs. However, severe water stress can actually inhibit the accumulation of sugar in grape berries. 
Although root restriction, as an environmental stress, has a significant effect on the phloem ultrastructure, the degree of damage to the phloem ultrastructure is limited and not severe under root restriction. Therefore, root restriction can promote sugar accumulation in grape berry.

\section{Literature Cited}

Bar-Tal, A., S. Feigin, and D. Sheinfel. 1995. Root restriction and $\mathrm{N}-\mathrm{NO}_{3}$ solution concentration effects on nutrient uptake, transpiration and dry matter production of tomato. Scientia Hort. 63:195-208.

Boland, A.M., P.D. Mitchell, I. Goodwin, and P.H. Jerie. 1994. The effect of soil volume on 276 young peach tree growth and water use. J. Amer. Soc. Hort. Sci. 119:1157-1162.

Carbonneau, A. and A. Deloire. 2001. Plant organization based on source-sink relationship: New findings on developmental, biochemical and molecular responses to environment, $\mathrm{p}$. 263-280. In: Roubelakis-Angelakis, K.A. (ed.). Molecular biology \& biotechnology of grapevine. Kluwer Academic Publishers, Dordrecht, The Netherlands.

Carmi, A. 1986. Effects of root zone volume and plant density on the vegetative and reproductive development of cotton. Field Crops Res. 13:25-32.

Costa, M.G., G. Vizzotto, and A. Maroe. 1992. Root restriction and growth manipulation in peach. Acta Hort. 322:221-230.

Fisher, D.B. and K.J. Oparka. 1996. Post-phloem transport: Principles and problems. J. Expt. Bot. 47:1141-1154.

Fisher, D.G. 1990. Distribution of plasmodesmata in leaves: A comparison of Cananga odoorata with other species using different measures of plasmodesmata frequency, $\mathrm{p}$. 199-221. In: Robards, A.W., Lucas W.J., Pitts J.D., Jong Sma H.J., and D.C. Spray (eds.). Parallels in cell to cell junctions in plants and animals. Springer-Verlag, Berlin, Germany.

Goto, T., T. Matsuno, Y. Yoshida, and Y. Kageyama. 2002. Photosynthetic, evapotranspiratory and leaf morphological properties of chrysanthemum grown under root restriction as affected by fertigation frequency. J. Jpn. Soc. Hort. Sci. 71:277-283.

Kempers, R., A. Ammerlaan, and A.J.E. van Bel. 1998. Symplasmic constriction and ultrastructural features of sieve element/companion cell complex in the transport phloem of apoplasmically and symplasmically phloem loading species. Plant Physiol. 116:271-278.

Myers, S.C. 1992. Root restriction of apple and peach with in-ground fabric containers. Acta Hort. 322:215-219.

Ogawa, T., H. Matsumura, and K. Gotou. 1997. Effects of rooting-zone restriction on 'Tomari' persimmon. J. Jpn. Soc. Hort. Sci. $66: 8-9$.

Patrick, J.W. 1990. Sieve element unloading: Cellular pathway, mechanism and control. Physiol. Plant. 78:298-308.

Patrick, J.W. 1997. Phloem unloading: Sieve element unloading and postsieve element transport. Annu. Rev. Plant Physiol. Plant Mol. Biol. 48:191-222.

Patrick, J.W. and C.E. Offler. 1996. Post-sieve element transport of photoassimilates in sink regions. J. Expt. Bot. 47:1165-1177.

Roberts, A.G., S. Santa Cruz, I.M. Roberts, D.A.M. Prior, R. Turgeon, and K.J. Oparka. 1997. Phloem unloading in sink leaves of Nicotiana benthamiana: Comparison of a fluorescent solute with a fluorescent virus. Plant Cell 9:1381-1396.

van Bel, A.J.E. 2003. The phloem, a miracle of ingenuity. Plant Cell Environ. 26:125-149.

Wang, S., G. Okamoto, and H. Ken. 1998. Effects of rooting-zone restriction on the changes in carbohydrates and nitrogenous compounds in 'Kyoho' grapevines during winter dormancy and early shoot growth. J. Jpn. Soc. Sci. 67:577-582.

Wang, S., G. Okamoto, H. Ken, J. Lu, and C. Zhang. 2001. Effect of restricted rooting volume on vine growth and berry development of Kyoho grapevines. Amer. J. Enol. Viticult. 52:248-253.

Webster, A.D., J.C. Atkison, and J.S. Vaughan. 1997. Controlling the shoot growth and cropping of sweet cherry trees using root pruning or root restriction techniques. Acta Hort. 451:643-649.

Yakushiji, H., H. Nonami, T. Fukuyama, S. Ono, N. Takagi, and Y. Hashimoto. 1996. Sugar accumulation enhanced by osmoregulation in Satsuma Mandarin fruit. J. Amer. Soc. Hort. Sci. 121:466-472.

Yang, T., L. Zhu, S. Wang, W. Gu, D. Huang, W. Xu, A. Jiang, and S. Li. 2007. Nitrate uptake kinetics of grapevine under root restriction. Scientia Hort. 111:358-364.

Zhang, D.P., Y.M. Lu, Y.Z. Wang, C.Q. Duan, and H.Y. Yan. 2001a. Acid invertase is predominantly localized to cell walls of both the practically symplasmically isolated element/ companion cell complex and parenchyma cells in developing apple fruits. Plant Cell Environ. 24:691-702.

Zhang, L.Y., Y.B. Peng, S. Pelleschi-Travier, Y. Fan, Y.F. Lu, Y.M. Lu, X.P. Gao, Y.Y. Shen, S. Delrot, and D.P. Zhang. 2004. Evidence for apoplasmic phloem unloading in developing apple fruit. Plant Physiol. 135:574-586.

Zhang, X.Y., X.L. Wang, X.F. Wang, G.H. Xia, Q.H. Pan, R.C. Fan, F.Q. Wu, X.C. Yu, and D.P. Zhang. 2006. A shift of phloem unloading from symplasmic to apoplasmic pathway is involved in developmental onset of ripening in grape berry. Plant Physiol. 142:220-232.

Zhu, L.N., S.P. Wang, T.Y. Yang, C.X. Zhang, and W.P. Xu. 2006. Vine growth and nitrogen metabolism of 'Fujiminori' grapevines in response to root restriction. Scientia Hort 107:143-149. 